\title{
INTERVENTIONS TO ASSURE RIGOUR IN A PROFESSIONAL PRACTICE DOCTORATE

\author{
Martin Andrew
}

\section{PREFACE}

Now in its fourth year, the Doctorate in Professional Practice (DProfPrac) within Otago Polytechnic's Capable NZ (College of Work-based Learning) faces a challenge to demonstrate its rigour to a range of internal and external stakeholders. Having celebrated its first completion in $202 \mathrm{I}$ and with others in the offing, now is an appropriate time to celebrate the intensity and authenticity of the organisation's distinct species of DProfPrac. In broad terms, the programme requires candidates to create new practice-led knowledge through a process strong in developing reflective and self-managing practitioners. The doctorate aims to implement and develop the Middlesex model of professional doctorates (Costley \& Lester, 2010); indeed, representatives of this organisation serve as annual external reviewers of the developing programme. The programme is also open to scrutiny from within, such as research quality gate-keepers and the broad doctoral mentoring team. Further, it is closely watched by other tertiary providers of similar qualifications, and those wishing to enter the doctorate space. Universities watch to see if the professional doctorate offers legitimate threat to traditional and thetic models of representing coming to know. Is it a threat? There is clear pressure on demonstrating the robustness of the programme and, in turn, each candidature's rigour.

Having a clear understanding of 'rigour' is crucial to the sustainability and quality assurance of programmes positioned at levels 9 and 10 on the New Zealand Qualifications Authority (NZQA) framework, particularly during times of 'super-complex' change. If, as Barnett (2000, 2004, 2017) might suggest, super-complexity is characterised by the constellation of critical moments comprising threats both inside the system (restructuring, amalgamation) and outside it (COVID-19, the world in turmoil, residual neoliberalist ideology), such educational providers must look to their sustainability to endure, and loss of survival would lead to rigor mortis.

\section{WHAT IS THIS ARTICLE?}

This article takes the form of a non-Cartesian subjective academic narrative, telling a research narrative emerging through ethnography and autoethnography (Arnold, 20I5). It is a story of multiple stakeholders and their voices - learners, mentors, research quality gatekeepers, governmental representatives - and their remembered utterances become part of this multi-vocal autoethnography. The following background paragraphs exemplify this pastiche or mosaic as I assemble and reorganise a description of the programme chorally, and the words of many echo throughout (Arnold, 2011; Sparkes, 2018). As the writer of a subjective academic analysis, I draw consciously from the corpus represented by professional practice scholars such as Costley, Elliot, and Gibbs (20I0) and Costley and Lester (2010); and unconsciously from everything I have heard or read about professional practice in the manner of all autoethnographers (Sparkes, 20I8).

The narrative traces a journey through the concept of 'rigour', eventually examining strategies to ensure it developed via practice from the DProfPrac's mentoring team, before heading towards another concept - one likely to replace 'rigour' as a descriptor as the decade wears on - 'doctorateness'. 


\section{TOWARDS UNDERSTANDING 'RIGOUR'}

In principle, the work-based practitioner research enquiry or design project generates rigour by contributing to new understanding of theory as it relates to the learner's professional practice or realm of endeavour. The doctoral work contributes to the solving of authentic dilemmas by taking an evidence-based and hence robust approach to problem-solving with as clear an understanding of potential outcomes as possible, although open to the vicissitudes of the unforeseen such as COVID-19. It also situates itself as much in the spaces of the learning process as in the product of enquiry, linking these two elements through sound acts of critical reflection, turning experience into learning.

Learners' work will also emerge from identifying a practical need in a specific context or environment and construct an appropriate line of enquiry to tackle that perceived opportunity; the line of enquiry, traditionally starting with a problem and a question, is less likely to emerge in practice models by finding a niche or gap in existing scholarship. Like the article I present here, the Capable NZ DProfPrac opens the door for nonCartesian and post-enlightenment representations of research (Arnold, 2015). Holistic in scope and futurefocussed in orientation, the professional doctorate is an instrument of and for ethical education and sustainability, affording social, environmental, and organisational impacts that can develop individual capability and create transformative change for immediate communities, ecologies and workplaces.

The legitimacy of any professional or creative doctorate model has benefitted from the opening up of alternative modes of knowing (Stock, 201I). The model has become safer in the 2020s and is more sustainable than the traditional, thetic research doctorate. The 'learner to educational organisation to workplace/industry partnership' speaks more to impact and sustainability than conventional modes of doctoral thesis. As late as 2009, Butt had observed that "there continues to be an undercurrent of snobbery in some parts of the academy, which claims that practice-based doctorates are somehow less intrinsically valuable than purely research-based doctorates, that 'thinking about' is more original than 'doing'" (p. 53). The greatest of risks is if such voices resound in the host organisation itself. Despite 'doubting Thomases', it is true that a large part of the legitimacy comes from the doctorate's potential for capacity-building by creating leaders in professional contexts (Boud et al., 202I). This potential for self-transformation and organisational empowerment in itself speaks to the theme of impacting sustainability.

\section{KEY DEFINITIONS}

Before we consider key interventions implemented by this species of DProfPrac to shore up the sustainability of the professional doctorate, we must first, a little playfully, enter the minefield of educational semantics. What is 'rigour' and how does it relate to 'quality assurance'? And what is 'super-complexity'? Are we tossing word salad if we speak of 'doctorateness'? This is a question I return to as the article closes as it anticipates the evolution of 'rigour' in doctoral contexts.

\section{Rigour}

There are key words that reverberate in the discourse of 'rigour' and its oak-like synonym 'robustness'. Grappling with and indeed embracing 'complexity' comes first, with demonstrating a clear and holistic intellectual and methodological 'grasp' being a key outcome (Winter et al, 2000). We also read in both the literature, policy and in-house curricular documents much about 'clarity' (helping others understand) and 'depth' (which I gloss as engagement with complexity). These relate to the communicative transmission of discovery and the application of analytical thinking and critical synthesis to acts of interpretation and presentation. The practical (applied), practice-based (fresh work, including scholarly, extending from a leading professional space of experiential knowing) or practice-led (creative, generative, iterative) work may accord with any of these adjectives: original, unique, innovative, inventive, distinctive, publishable, impactful, transformative, and inspiring of change. All these adjectives beg the critical questions 'to or for whom?' and 'in whose interests?' 
In contrast, traditional modes of qualitative research in higher education, as opposed to work-based professional practice, align with even more abstract concepts such as credibility, transparency, analysability, generalisability, validity, and usefulness, (Roller \& Lavrakas, 2015) - to whom I also ask, 'to and for whom?' The abstract nature of such nouns obscures the fact that such concepts are hard to measure objectively. Thus, a feature of the professional doctorate, like creative ones, is to accept, absorb and celebrate the inevitability of the subjective and the generative and critically locate it as an essential aspect of the work's uniqueness. It allows the "muddled, idiosyncratic fluid eccentricities that make us unique" (Muncey, 20I0, p. xi.) rather than bracketing them off as facets that muddy rather than clarify the waters. A method broadly known as 'the self as data' (Arnold, 20II) manifests itself often as one of the many species of autoethnography that reflect and refract a worldview through acts of showing and telling, such as narrative and vignette writing. The rigour in this model of doctorate comes in part from the interplay of 'reflectivity' and 'criticality', and in part from a convincing argument for 'doctorateness.' These are three concepts to which we return.

Roller and Lavrakas (2015) offer what is arguably the most definitively quality-focused model of qualitative research. In their work, the methods for ensuring research throughout the lifespan of the research include: thorough rationales for the necessity for the research via context mapping or needs analysis; 360-degree grounding in recent scholarship; quality project and 'instrument' design, including controls for variables and critiques for participant selection and sampling methods. There will be an emphasis on the 'density' or 'thickness' of the 'data' and the explicability of the logic behind the finding of connections or patterns in the sense-making process and the saturation thereof. Interviewers and observers need to be skilled with consistent instruments. We will expect consistency in data collection, analysis and presentation and an enrichment of transparency in any ethnographic elements.

Before your head explodes and you wonder how long a piece of string is, we need to remind you that our scale is that of a doctorate, not a Nobel prize (Mullins \& Kiley, 2002). Further, we can take stock from the observation that the principles behind the Roller and Lavrakas model of quality research align with some central concepts underpinning professional doctorate work. These facets include an eschewing of the possibility of 'truth' and an emphasis on context-environment, meaning-generation, and the participant-researcher relationship, all of which are to be examined closely (read: reflectively and critically). It affords, too, a measure of design flexibility though the professional doctorate offers more. Potentially, as Mann (2020) indicates, in its imagined fourth generation iteration, the heutagogical-based professional doctorate can accommodate the crazy messiness of professional life and indeed its super-complexity by aligning the practice journey with an advanced frame of professional practice.

Alongside the features of old and new versions of the professional doctorate, work will speak to the originality agenda by incorporating what Dolan (2015) called "a succinct, focused, critical appraisal of the specific contribution to knowledge" (p.I I), possibly in the form of an extended critical reflection. Like modern creative doctorates, the professional doctorate allows the messy, the unfolding and the emergent. It can also align with the tenets of transdisciplinarity, focussed on thorough stakeholder involvement in collaborative project work responding to a particularly wicked problem. It is a space of huge potential.

\section{Quality assurance}

Quality assurance belongs to the discourse of institutional and national policy, and conveys compliance and surveillance. In NZQA's outline of the qualities of Level 10, the level of 'doctorateness', we find the usual buzzwords: "Critical reflection on existing knowledge or practice and the creation of new knowledge" (NZQA, 2020, p. 30). We also read about the 'culmination' of research and the conclusion of the researcher journey being characterised by increased 'independence' in scholarship. We read of the substantiality and originality of the work and its quality assurance by 'recognised experts' who both guide and assess the work. Importantly, quality in process is assured by mentors, advisors, or supervisors while a quality product is figured by the readings of examiners. Both mentors and assessors will be members of the kind of community of practice to which the learner may aspire. 
There is a temporal measure - at least two years' fulltime enrolment to show 'sustained commitment'; and one using the quantitative logic of the system - 360 credits. In describing the application of knowing and skills, the wording is measured: you must show "sustained commitment to the professional integrity and to the development of new ideas or practices at the forefront of discipline or professional practice" (NZQA, 2020, p. 30). The concept of professional integrity is as close we get to ethical rigour in the discourse of compliance. With 'forefront' connoting vanguards and spearheads, not even NZQA can escape from metaphor: 'doctorateness' consists in the contribution of "knowledge at the most advanced frontier of a field of study or professional practice." Cowboys, Indians, and Captain Kirk vie for space in my brain, and I muse on how 'culmination', like zenith, is a stellar and astronomical term. Clearly NZQA think doctoral learning is like Star Trek (prior to William Shatner's real flight to space).

The modes of quality assurance at national level, as at institutional level, are underpinned by self-assessment and include accredited entry processes as well as ongoing risk management alongside occasional (usually annual) consistency reviews, external moderation, independent monitoring and external evaluation and review (NZQA, 2020).

\section{Super-complexity}

Doctoral professional practice learners are afforded an opportunity to create what Barnett had in 2004 called "authentic being" (p. 259) in his germinal 'real world' study of learning for an unknown future. Such moments as 'the COVID moment', any organisational restructure, or the mergser of Te Pukenga remind us that engaged real-world responsiveness in education has the capacity to create in the practitioner-researcher "a self that is adequate to such an uncertain world" (p. 254).

This 'adequacy' is achieved through "encountering strangeness ... wrestling with it and ... forming one's own responses to it" (Barnett, 2004, p. 257). The strategy for achieving this is, of course, reflectivity, "a meaningmaking process that moves a learner from one experience into the next with deeper understanding of its relationships with and connections to other experiences and ideas" Rodgers (2002, p. 845). Making sense of mayhem, Barnett maintained in 2000, remains a constant function of higher education, even in the supercomplex age where knowledge lacks status and legitimacy in an era hijacked by rampant neoliberalism.

Critiquing the neoliberalised place of learning, Bengtson (2017) demonstrated how prescient Barnett's notions (from 2000, 2004, and others) has been, and 2020's COVID moment demanded methodological and ideological flexibility not the linear Cartesian rigidity of traditional knowing. What higher-vocational learning needs is to be, in Barnett's terms, open, bold, engaging, accessible, and, above all, conscious of its own insecurity. This necessity requires the application of strategies and pedagogies that emphasise our mutual project of 'being and becoming' through practice and move beyond the worries of measurement and surveillance to embrace the hope and community impact that professional practice doctorates afford. One of the strategies that enables moving beyond what Foucault (1980) calls 'forms of thought', or 'regimes of truth' is criticality, an instrument for disrupting master narratives like 'neoliberalism is the only way forward' and breaking down both dominant and taken-for-granted notions. Barnett's vision represents a mature educational philosophy where learning stems from bravely encountering dilemmas and disequilibrium and ideally results in grounded learners and community well-being. These are also results we would also hope to see from a professional doctorate.

Learning for a super-complex world requires the application of two core features of rigour: criticality and reflectivity. Critical reflectivity, Murray and Kujundzic (2005, p. 4) tell us, "can increase our intellectual independence, increase our tolerance for different points of view, and free us from the snares of dogmatism ... Critical thinking invites us to call the bluff of accepted dogmas." Criticality involves being aware of our own theories of knowing and how we see the world, hence the ocular metaphors in research methodology of lenses, prisms, mirrors, and lights. It affords an action of moving beyond generalisation and description into creating 
linkages between the previously known and the recently discovered to generate new meanings. It involves both analytical unpacking and unravelling to move beyond assumption into fresh possibilities and synthesising so that the fresh and the emergent can make new meanings in the light of knowledge already embedded in existing scholarship and professional documentation.

Such a description of criticality brings us to its borders with reflectivity, which, Rodgers (2002, p. 845) tells us, also consists in "the thread that makes continuity of learning possible, and ensures the progress of the individual and, ultimately, society" and "a systematic, rigorous, disciplined way of thinking, with its roots in systematic inquiry." Reflectivity grounds our enquiry in real world contexts, ethical systems, and communities where we co-construct learning with others. It offers, Clutterbuck and Hirst (2003) famously argue, "an opportunity for discovery through dialogue", affording insights that teach us "new tactics, greater self-awareness and greater ability to manage oneself and others, and the establishment of clearer priorities" (p. 104). What the professional world of the 2020s needs most, I contend, is the critical, reflective practitioner. It comes with the territory with the rigour of professional doctorates.

In the light of the above discussions of rigour (bottom-up) versus quality assurance (top-down) and the necessity for professional doctorates to afford criticality and reflectivity as registers of robustness, I want to turn, now, to six features or 'interventions' of the Capable NZ Doctorate in Professional Practice that contribute to the generation of rigour.

\section{SIX INTERVENTIONS}

The six interventions I introduce here come under the following headings: alignment with bicultural frameworks; sustainability in the programme structure; levels of mentor support; the criticality gambit; leveraging the politics of evidence and lastly, without a proctological thought in mind, tightening the back end.

I will start by addressing the first two interventions of bicultural alignment and sustainability. The programme's three stages create a trajectory of being and becoming for the learner that also embeds sustainability, a facet of rigour, at the programme, institutional and national levels. This process also articulates with the quality assurance descriptors implemented by NZQA. The first third of the programme structure both audits a candidate's professional learning through a critically reflective work known as a review of learning, and proposes a plan for action and enquiry, also critically reflective, known as a learning agreement, a placeholder term for the proposal of traditional models. In these two courses within the programme, learners select and justify sustainable approaches to tasks, problems, or dilemmas, considering how their work might impact others' capacity as well as their own. Thus, sustainability is considered not only in relation to the emerging professional self, but also to communities which might benefit. A critically reflective process of considering how the study might involve or benefit Māori ensures a rigorous interrogation of alignment with biculturality, and upholds the programme's commitment to Te Tiriti o Waitangi. The bicultural requirement, while common throughout professional doctorates in Aotearoa New Zealand, validates indigenous ways of knowing and representing knowledge in a rigorous and sustainable way.

Learners must pass these courses to progress to the final two thirds, the practitioner enquiry or 'thesis' equivalent, which can manifest itself in manifold forms. This process enables learners to play a unique role in implementing change, developing innovative approaches and creating sustainable solutions to complex issues (Costley \& Lester, 2010).

Thirdly, the programme draws on a range of professional doctoral mentors, many of whom are 'doctored' professional practice staff or members of the broader organisation from the disciplines. Those mentors with a record of doctorate completions, 'specialisms' in work-based learning, and practitioners in the realms of mentoring and coaching, work collaboratively with less experienced mentors, enacting the capacity building that 
I argued above was essential to sustainability. In addition to the peer support inherent in mentoring dyads or teams, the organisation runs programmes of doctoral education training in addition to a particular intervention: the professional doctorate mentor community of practice, where experienced and core members share mentoring discourse and knowledge repertoire with the broader group. Although there are major challenges with organising time, this community functions effectively to build capability and discuss dilemmas as well as addressing formal, methodological and procedural issues. Since NZQA emphasises the role of the 'guide' in assuring the quality or rigour of the doctoral journey, it is crucial to offer a site where practice is discussed and critical reflectivity modelled. Further, those mentoring learners have an open-diary invitation to consult with an experienced mentor for critical friendship.

Fourthly, the criticality gambit ensures that not only do mentors reflect critically in their pedagogical being in the context of this doctorate, they also become conscious of areas needing practice and experience and they implement a conscious programme of ongoing professional development. The criticality gambit relates to learners as well, since criticality is the subject of additional material available to learners via the learning management system and is also the focus of mentor-led learner development seminars. Since many learners on the programme are practitioners from workplaces, we can anticipate that criticality might be a weakness in their thinking and production. Building criticality in the first year of the programme is a conscious pedagogical imperative in the programme, affording learners who begin the practitioner enquiry to be possessed already of a strong ability to apply critical thinking to their research project. The ethics and indigenous knowledge application processes that accompany the first year are further opportunities for applied criticality. In the final stages of the programme, when learners in theory become autonomous experts, the mentor's role becomes identifying further opportunities to leverage criticality in the writing or other thetic outputs.

Fifthly, the accountability function of a doctorate journey requires evidence of emerging practice and advancing thought. The tripartite structure of the programme as outlined above affords the continuous production of evidence of enquiry so that the final submission is a portfolio of outputs generated during the period of candidature. In later stages of the candidature, meetings with mentors are earned on the basis of paying forward with work - evidence of practice and becoming. In meetings, work can be workshopped or the site of onthe-spot critical commentary. This process maximises the value of the limited mentor-to-learner sessions and ensures a continuous record of evidence is maintained to chart the journey of progress. Other evidence this process generates might take the form of maintaining a reflective learning journal or participation in professional communities which can be evidenced with outputs.

Finally, at the back end of the programme, when learners might be on their penultimate draft, an external expert reader processes the penultimate draft and offers feedback on lifting the work to mentors. This process ensures a more objective pair of eyes evaluate the work, seeing weaknesses mentors might be blind to owing to their closeness to the work. This process can enable the negotiation of a final draft which is more likely to meet the approval of examiners. As NZQA's quality assurance guides indicate, the selection of appropriate assessors is a further way of ensuring quality or rigour to the individual output and hence to the programme. A range of internal quality assurance panels vet the nominated examiners and assess their suitability to examine a particular work using such criteria as methodological alignment and examination experience. Placing the output in the context of national and international external experts ensures its acceptability and doctorateness at the highest level - the level of the peer to the community of practice of professional practitioners. The above process, tightening the back end, enables the individual to know that their work is acceptably and rigorous in terms of its doctorateness in the eyes of qualified experts.

As I head towards a conclusion where the concept of 'doctorateness' is developed to indicate the future directions of rigour, I move on from a key section where six local practices for ensuring rigour have been addressed. In concluding this way, I eschew the Cartesian notion that conclusions are for recapitulations. Why would you want to read again what I said above? This conclusion serves to look to the future. 


\section{CONCLUSION: TOWARD 'DOCTORATENESS’}

As the journey to define 'rigour' intensifies into the 2020s, it is increasingly expected to align with the idea of 'doctorateness.' This notion belongs to the discourse of debating what creative and professional forms and media constitute and represent doctoral knowing. The term 'doctorateness' is increasingly used as a determiner of rigour in all species of doctorates, thus enabling comparisons of all species of doctorates from the traditional to the professional to the creative or performative. 'Doctorateness' is an abstract noun that captures the concept of rigour, complete with high levels of criticality and reflectivity. Trafford and Leshem (2009) see it as a threshold concept where key components like conceptual framework, contribution to knowledge, appropriate methodology and clear presentation converge, making it theoretically more than the sum of the doctoral examination criteria. I believe that 'doctorateness' is a term that works synergetically with Barnett's (2004) idea of learning for an unknown future, allowing critically reflective expression of encounters with the unexpected in the context of the learner journey. Doctorateness is an expression of response to complexity; indeed supercomplexity. How practitioners wicked-problem-solve and reorient themselves in the face of dilemmas becomes a fundamental part of their experiential and transformative learning.

Evaluating the potential for doctorateness occurs when learners present their research to a pseudo-examination panel when they are assessed for their learning agreement in both textual (or other evidential output) and performative or presentational media. Those judged as lacking evidence of doctorateness or rigour are given feedback or feed-forward to enable them to reconfigure their proposals for requisite depth and breadth.

Studies of doctorateness continue to grapple with the concept despite a changing tide in its favour (Stock, 20II), and research into what it looks and feels like in practice continues. Yazdani and Shokooh (2018) see 'doctorateness' as

A personal quality, that following a developmental and transformative apprenticeship process, results in the formation of an independent scholar with a certain identity and level of competence and creation of an original contribution, which extend knowledge through scholarship and receipt of the highest academic degree and culminates stewardship of the discipline (italics mine).

This definition addresses the aspects of rigour that align with quality assurance, but does not address the issues of emergence and complexity, the ability of candidates to pivot in their methodological approach and ability to communicate findings in light of external dilemmas such as Covid-19. It is not yet a model of doctorateness for a super-complex world. This thinking on one's feet - Barnett's (2004) encountering the 'strange' and Dewey's (1938) learning via disequilibrium, involving Schönian reflecting in as well as on and for action (Schön, 1991) - is surely a key attribute of doctorateness in a professional practice doctorate in professional practice.

There is clearly more to do in outlining the parameters of doctorateness in emerging forms and there are many more voices to heed and represent, but in the meantime it is wise for institutions offering such programmes to ensure and position their programmes as duly rigorous before further storms of super-complexity rage and return the rigour to rigor mortis. 
Martin Andrew operates as a creative mentor in postgraduate programmes, including Master and Doctorate degrees in Professional Practice. Prior to his four to five years supporting the College of Work-based Learning in Otago, New Zealand, he had sojourned away from his hometown of Otepoti/Dunedin with two honorary posts at Melbourne universities in Creative Industries and Trans-national Education (TNE). His work and research have become increasingly focussed on doctorate education and supporting learners to reach their own personal best through critically reflective practice and writing. A transdisciplinarian, he emphasises that his past disciplines have included Education, Drama, Linguistics and Writing, Creative and otherwise. He holds honorary positions in Australia, Vietnam and Indonesia.

(D) https://orcid.org/0000-0002-0108-5195

\section{REFERENCES}

Arnold, J. (20II). The self as data: A qualitative methodology, Journal of Educational and Developmental Psychology, II(I), 65-73.

Arnold, J. (2015). Research as stories: an academic subjective analysis. Advances in Research, 4(I), 59-66. http://doil 0.9734/ AIR/20I5/13050

Barnett, R. (2000). University knowledge in an age of supercomplexity. Higher Education, 40, 409-422.

Barnett, R. (2004). Learning for an unknown future. Higher Education Research \& Development, 23(3), $247-260$.

Barnett, R. (2017). Researching supercomplexity: Planes, possibilities, poetry. In L. Ling \& P. Ling (Eds.), Methods and paradigms in education research (pp. 29I-308). IGI Global.

Bengtson, S. E. (2017). Supercomplexity and the university: Ronald Barnett and the social philosophy of Higher Education. Higher Education Quarterly, 72(I), 65-74.

Boud, D., Costley, C., Marshall, S., \& Sutton, B. (2021). Impacts of a professional practice doctorate: a collaborative enquiry, Higher Education Research \& Development, 40(3), 43I-445. http://doi: I0.1080/07294360.2020.1765744

Butt, M. (2009). Creative writing research degrees: range and rigour. International Journal for the Theory and Practice of Creative Writing, 6(1), 53-56

Costley, C., Elliot, G., \& Gibbs, P. (2010). Doing work-based research: approaches to enquiry for insider-researchers. Sage.

Costley, C. \& Lester, S. (2010). Work-based learning at higher education level: value, practice and critique. Studies in Higher Education, 35(5), 56I-575.

Clutterbuck, D., \& Hirst, S. (2003). Talking business: Making communication work. Butterworth-Heinemann.

Dewey, J. (1938/1986). Logic: The Theory of Inquiry. In J. A. Boydston (Ed.), The Later Works of John Dewey 1925-1952, volume 12 (pp. I-539). Southern Illinois University Press.

Dolan, G. P. (20I5). Originality and the PhD: what is it and how can it be demonstrated? Nurse Researcher, 22(6), II-15.

Foucault, M. (1980). Power/Knowledge: selected interviews and other writings 1972-1977 (ed. C. Gordon). Pantheon.

Mann, S. (2020). Shape of professional practice research. Scope contemporary research topics: work based learning, I, 22-31.

Mullins, G. \& Kiley M. (2002) 'It's a PhD, not a Nobel Prize': how experienced examiners assess research theses. Studies in Higher Education, 27(4), 369-386.

Muncey, T. (2010). Creating autoethnographies. Sage.

Murray, M. \& Kujundzic, N. (2005). Critical reflection: a textbook for critical thinking. McGill-Queen's University Press.

New Zealand Qualifications Authority (NZQA, 2020). The New Zealand qualifications framework. The New Zealand Government.

Rodgers, C. (2002). Defining Reflection: Another look at John Dewey and reflective thinking, Teachers College Record, I04, 4, 842-866.

Roller, M. R., \& Lavrakas, P. J. (2015). Applied qualitative research: A total quality framework approach. Guildford Press.

Schön, D. (|99|). The Reflective Practitioner. Ashgate.

Sparkes, A. C. (2018). Autoethnography comes of age: consequences, comforts, and concerns, In D. Beach, C. Bagley \& S. Marques da Silva (Eds.), The Wiley Handbook of Ethnography of Education (pp. 479-499). John Wiley \& Sons. 
Stock, C. F. (20II). Approaches to acquiring 'doctorateness' in the creative industries: An Australian perspective. In L. Justice \& K. Friedman (Eds.), Pre-Conference Proceedings: Doctoral Education in Design Conference 2011 (pp. I-II). Hong Kong Polytechnic University.

Trafford, V., \& Leshem, S. (2009). Doctorateness as a threshold concept. Innovations in Education and Teaching International, 46(3), 305-15.

Winter, R., Griffiths, M., \& Green, K. (2000). The 'academic' qualities of practice: what are the criteria for a practice-based PhD? Studies in Higher Education, 25(I), 25-37.

Yazdani, S., \& Shokooh, F. (2018). Defining doctorateness: a concept analysis. International Journal of Doctoral Studies, I3, 31 -48. https://doi.org//0.28945/3939 